\title{
EXPERIENCING THE INACCESSIBLE. A FRAMEWORK FOR VIRTUAL INTERPRETATION AND VISUALIZATION OF REMOTE, RISKY OR RESTRICTED ACCESS HERITAGE PLACES
}

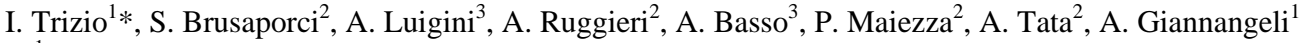 \\ ${ }^{1}$ Institute for Construction Technologies, Italian National Research Council, ilaria.trizio@itc.cnr.it \\ ${ }^{2}$ Dept Dep. of Civil, Construction-Architectural and Environmental Engineering, University of L’Aquila \\ ${ }^{3}$ Free University of Bozen, Faculty of Education
}

\section{Commission II, WG II/8}

KEY WORDS: Virtual Reality, Augmented Reality, Virtual Museum, Architectural survey, Architectural Heritage, Heritage Interpretation

\begin{abstract}
:
In order to be properly handed down, especially in particular conditions with a high rate of vulnerability, cultural heritage requires documentation and enhancement strategies. The case study presented in this paper is particularly critical not only for the conservation conditions, but especially for the environmental conditions: the Catacombs of San Vittorino have complex conditions of recovery, because of the nature of the artefact and because of the poor lighting of the main environments. For this particularity, a workflow was developed that, in order to achieve the creation of an immersive device navigable by digital viewers such as Oculus Rift or similar, required the start-up of shooting by laser scanning, and then treat the point cloud with different software, in order to obtain a satisfactory result that, in other contexts, could have started easily from a photogrammetric shooting.
\end{abstract}

\section{INTRODUCTION}

\subsection{General context of the project}

Information and education in Cultural Heritage represent, as amply demonstrated by the international and national debate, a necessary condition on which to base the strategies of conservation and enhancement of cultural and naturalistic assets and, consequently, also the activities of tourism promotion and offer of services to the large public.

In the scientific panorama, research activities and contributions regarding vulnerability and the risk of loss of cultural heritage are extremely current like the ways in which the heritage should be placed at the center of attention of the political and private world, representing one of the most important flywheels to restart the economy of the countries.

In parallel with this issue, is very actual research about the manner to enhance and use sites and assets at risk, irremediably lost or inaccessible to the public.

The research project described in these pages, developed by a research group involving scholars of the University of L'Aquila, of the University of Bolzano and CNR researchers, was conceived in order to combine the need to preserve memory, through digital documentation, of a cultural site located in a territory with a high seismic risk, and to guarantee its knowledge and use through AR and VR applications.

The object of the research is the combination of a laser scanning survey with an application of virtual reality starting from the acquired point cloud in order to be able to use virtually the San Vittorino catacombs, a suggestive site, with particular environmental conditions, indicated as the oldest paleochristian site of the Abruzzo region.

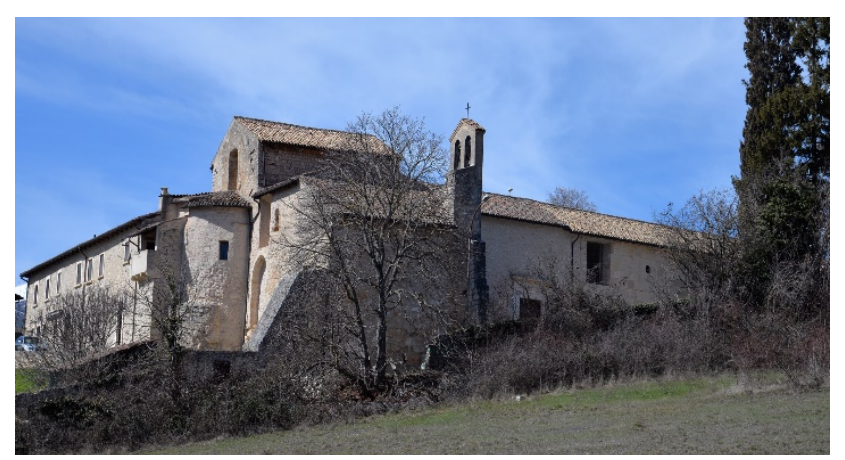

Figure 1. The catacombs of San Vittorino are excavated under the church of San Michele Arcangelo, type with a single nave, where you can access from the transept and the bottom of the nave.

\subsection{Inaccessible assets}

It is now an established fact that accessibility to cultural heritage is an essential right for the development of the person and the communities, as well as an essential requirement for the itself existence of cultural heritage. Cultural Heritage in fact it is defined, preserved, transformed and expresses its educational potential only and exclusively if it is used, understood and recognized as such by the citizens (Bortolotti et al., 2008).

Among the various meanings of accessibility linked to cultural heritage there is the cognitive one, which is related to the ability to understand the meaning of the heritage. In order to reach this

\footnotetext{
* Corresponding author
} 


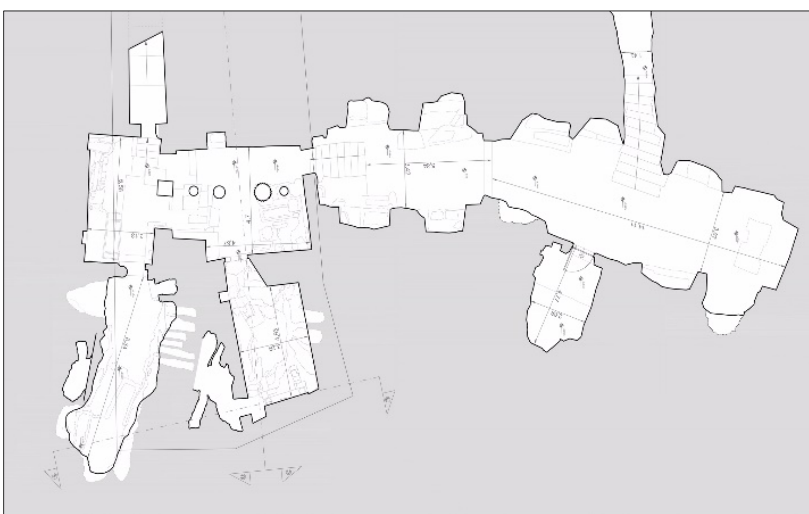

Figure 2. Planimetric survey of the entire complex of the catacombs.

purpose it is necessary to prepare a process of Interpretation of the assets, in line with was enunced in the Ename Charter (Trizio et al., 2017), which is careful, scientifically documented and which uses clear and diversified languages, tools and methods according to the needs of the different target of users (Italian National Plan for Cultural Heritage Education). In light of this fact, the institutions responsible for managing the assets are required to make them accessible, modulating times and methods of their use in relation to the needs of protection of the assets themselves (Bortolotti et al., 2008).

In this context, new technologies represent the suitable tools to document, study and communicate cultural and landscape assets. Digital technologies are indispensable resources for the enhancement and education of heritage itself, because they allow the creation of faithful digital representations of the assets (digital twins represent for example the paradigm of Industry 4.0 on Cultural Heritage) that can be used as a complement to direct use or when the originals are, for several reasons, hidden or inaccessible (Bortolotti et al.).

Scientific literature has numerous examples of ICT experimentations to improve accessibility and use of hidden sites (Bonacini et al., 2013) or almost completely inaccessible sites (Beraldin et al., 2011) or for the documentation of sites at risk, now irretrievably destroyed (Archeomatica, 2017) or simply for online tour of sites and complexes that are private property.

This broad context necessarily requires an interdisciplinary team, and in fact our research group started from this awareness and from the consideration that our cultural heritage represents a set of resources in evolving to be rebuilt in their meanings, as well as a resource for reflecting, questioning, recognizing and expressing itself.

Based on these considerations, the virtual fruition project of the San Vittorino catacombs was carried out, in continuity with a previous study aimed to reach the knowledge of historical artefacts starting from their three-dimensional parametric modeling (Brusaporci et al., 2018, Luigini et al., 2019).

With these assumptions has been developed a system that makes use the most current technologies of representation and use - immersive virtual reality and augmented reality - to create a path of knowledge of the building that can be used both remotely and in situ.

The development of virtual reality and augmented reality technologies continue to progress and spread, and in fact the use of VR and AR offers many possibilities and advantages from many points of view: planning and management of cultural heritage asset; entertainment, because the models and their navigation can be a real tourist attraction; an additional way to share knowledge, as potential educational tools (Luigini, 2019).

\subsection{The study case}

The catacombs of San Vittorino are located in the homonymous hamlet of the municipality of L'Aquila and represent the most important early Christian cemetery of Abruzzo (Somma, 2012). The entire area, excavated on the hill which dominates the remains of the Roman city of Amiternum, was probably used for cemetery purposes even before the arrival of the Christians in the area (Sidor, 2016) and, after the construction of the tomb of San Vittorino (Pani Ermini, 1975), it was developed a real cemetery whose first settlement dates back to the 4th century a.C.

At the present the complex (Fig. 1) consists of a church with a single nave located above the catacombs in which it possible to access from the transept and from the bottom of the nave.

The church is divided in two by a wall that separates the "old church", to the north of the complex, with the church of San Michele Arcangelo, the only one currently in use. According to the sources, the presence of an "ecclesia sancti Vittorini" is attested since the eighth century B.C. and the most important renovations of the complex, according to the dating elements found inside the building, date back to 1170 and 1312 .

The complex of the catacombs instead consists of a long corridor which leads to a large gallery, which develops perpendicularly to the axis of the church, and from six rooms, destined to host the martyr's tomb and the burials of the faithful. Three of these have a more or less regular plant, with masonry walls and vaults covered while the others are carved into the rock or obtained from natural cavities (Pani Ermini, 1975).

The original entrance to the catacombs, which is currently closed, was located inside the old church and led directly to a rectangular room, with a barrel vault, inside which is the presumed tomb of San Vittorino, whose arrangement is dated to the fifth century A.C. and wanted by the bishop Quodvultdeus who had realized it with material from the archaeological site of Amiternum and with coeval marble reliefs (Somma, 2012).

From this environment it is possible to access a cave with some tombs made with variable techniques, realized according to the available space.

The catacombs, owned by the Vatican State, after 12 years of closure, were reopened to the public only recently, in 2016, after the restoration carried out by the Pontifical Commission for Sacred Archeology of the Vatican, which lasted over a year.

Currently the cemetery complex is one of the most important religious tourism destinations in the area and can only be visited on weekends, but only by reservation.

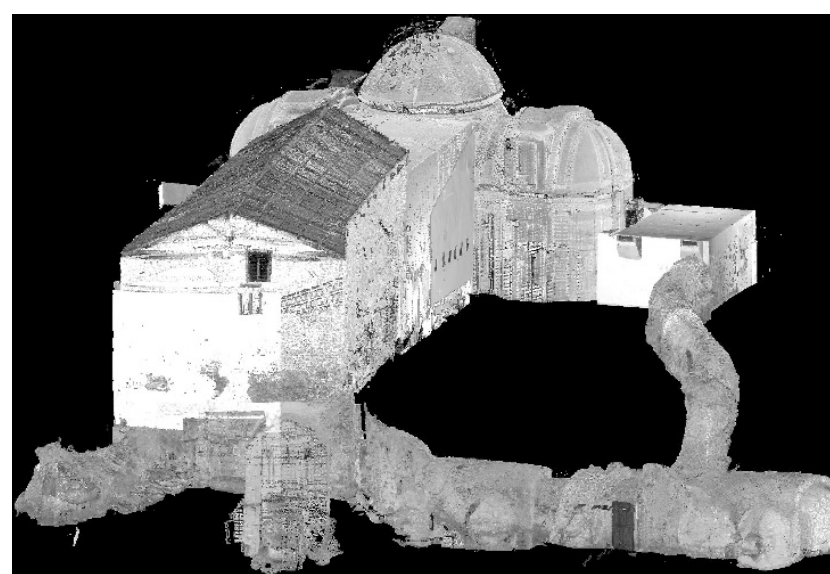

Figure 3. Laser scanner survey of the complex of the upper church and the underground connections of the catacombs. 


\section{THE SURVEY OF THE CATACOMBS OF SAN VITTORINO (STEFANO ET AL., MAX. 6000 CARATTERI, SPAZI INCLUSI)}

The San Vittorino catacombs have been the subject of two different digital surveys that, carried out at a distance of a few years from one another, have used two different types of laser scanners (Bianchini, 2014; Gaiani, 2012).

In the first, performed in 2016 and relating to the entire architectural complex of the San Michele Arcangelo church under which the catacombs twists and turns - the instrument employed was the phase difference scanner Leica HDS6200, characterized by a full field of view (FOV) of $360^{\circ}$ x $310^{\circ}$ (Paris et al., 2016; Rodriguez-Navarro, 2017).

In choosing the station points and shooting resolution, the geometric and dimensional characteristics of the spaces to be surveyed were taken into account, with the aim of obtaining a point cloud that is as homogeneous as possible, with shadow areas minimised (Bianchini et al., 2015; Clini et al., 2019).

A total of 46 scans were carried out as follows: 21 outside the architectural complex, 14 inside, 9 inside the catacombs, 2 in the passage connecting the catacombs and the church.

Because of the small size of the catacombs spaces, an average resolution level was adopted, corresponding to an increase in azimuth and zenith angle of $0.072^{\circ}$ and a point density of 3.14 $\mathrm{cm}$ at $25 \mathrm{~m}$.

The individual scans were joined together - within the Leica Cyclone software - using mainly procedures for automatic recognition of moving targets. For the connection between external and internal, we proceeded with manual registration operations, consisting in identifying a series of homologous points between the two cloud points.

Finally, the RGB color value obtained from spherical panoramas, created for each scan (with the exception of the catacombs) through a camera kit external to the laser scanner, was added to the metric data of the church point cloud.

The second survey campaign, carried out in 2019 with the Faro Focus S70 laser scanner, equipped with an integrated camera, involved exclusively the catacombs.

Unlike the 2016 survey, where, due to low light issues, the color data had not been acquired, the second campaign was able to exploit the possibilities offered by the HDR (High Dynamic Range) (Battini, Vecchiattini, 2018).

The aim of the survey was to obtain a point cloud whose characteristics, both in terms of point density and color, could be the basis for the virtual fruition of an asset that, otherwise, is not accessible.

In consideration of this purpose and the need to contain acquisition times, it was decided to pay more attention to the communicative aspect of the point cloud rather than to its quality, intended as noise reduction in the scan data (Nespeca, 2018; Moreira et al., 2018;).

Thus, 18 laser scans were produced with a resolution corresponding to a point density of $6.1 \mathrm{~mm}$ at 10 meters from the instrument (resolution $1 / 4$ ), 5 exposures for each shot and $2 \mathrm{x}$ quality.

Subsequent to the procedure of data acquisition, the production of the point cloud has been carried out into the software SCENE_2018.0.0.648 by FARO.

After importing the data acquired by the laser scanner inside the scanning project, the processing of each scan has been made: the colour has been applied and, then, a rendering of the points was made on the basis of the spherical panorama automatically composed by the scanner through the assembly of the images acquired during the capture phase. The spherical targets of radius $0.0695 \mathrm{~m}$ (inputted value) have been automatically recognized by

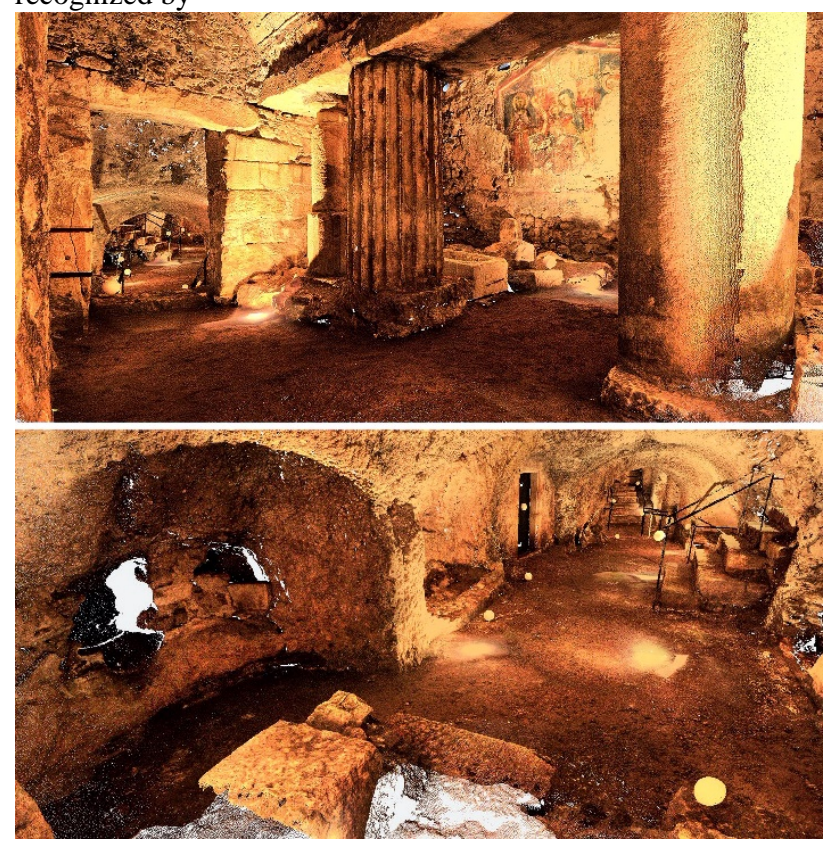

Figure 4. Laser scanner cloud points with chromatic component of some central areas of the catacombs.

the software. Later, we proceeded to a correction of this last step,by removing the target property from objects that have been erroneously recognized as such by the software.

The registration phase follows, which has been carried out through a visual procedure, i.e. by placing the scans in a global view and aligning them by dragging with the mouse.

Before proceeding to the final step, it has been necessary to fix some issues regarding the colour data, arisen as consequence of the particular lighting condition: the ambient surveyed was artificially enlightened by spotlights embedded in the ground. The resulting situation was of strong light and shade, in which the lights were characterized by a hard warm colour cast. Consequently, we chosen to use during the image capture the HDR feature setting it at 5 exposures, in order to obtain a dynamic range such as to allow a realistic visual perception of the surveyed ambient.

Among the various parameters involved in the exposure determination (automatically set by the integrated camera of the scanner), the one related to the white balance has been particularly important, whose setting determines the colour cast of the resulting image. Despite the real situation perceived by the human eye was that of a warm colour temperature determining a colour cast in orange tones, the automatic white balancing of the integrated camera has led to a colour cast in the shades of blue in 9 captures over 18.

In order to avoid in the visualization phase disturbing chromatic unevenness, resulting from the different colour cast, we chosen to fix them. In SCENE it is possible to operate minor adjustments regarding the image editing into the properties of the HDR image automatically composed, but they are simple pre-sets and so not enough to achieve our purpose. We decided so to export the spherical HDR panoramas in order to process them within Adobe Photoshop software, specifically designed for managing this kind of issues. So in Photoshop we rectified the blue colour cast through the match colour feature, taking as reference a spherical panorama with orange colour cast.

The images processed and fixed have been re-imported in SCENE and so re-applied to the point cloud, finally uniform 
from the chromatic point of view. We proceeded finally to the elaboration of the project point cloud. about 569880488 points with color component, can be considered more suitable to obtain a polygonal model suitable for a virtual transfer on an interactive platform. The use of the

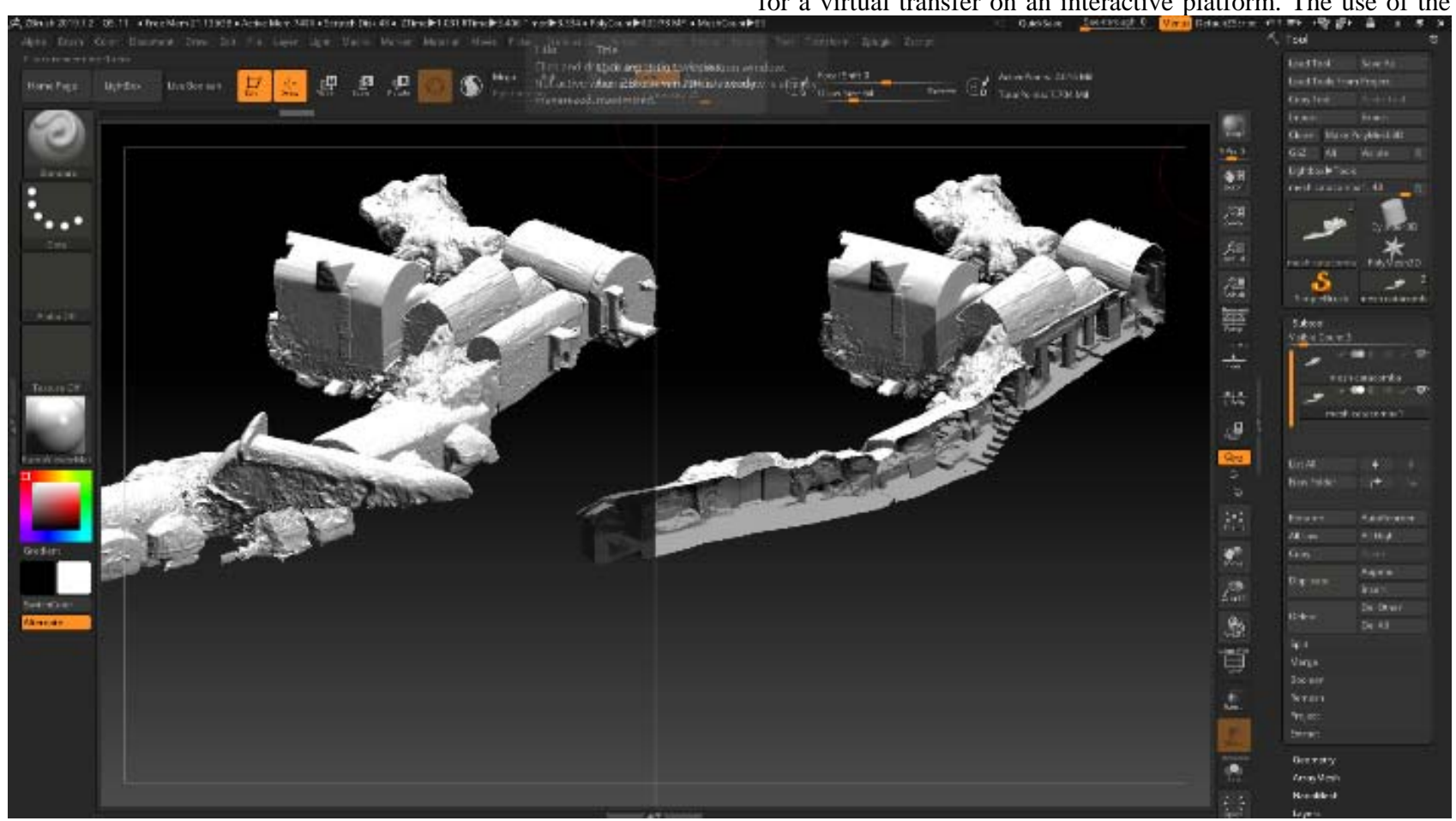

Figure 7. Optimized model of the catacombs, interactive section

of a central area of the corridors using Zbrush software.

\section{MIGRATION WORKFLOW ON A VIRTUAL EXPLORATION PLATFORM: FROM THE CLOUD POINTS OF LASER SCANNER TO THE POLYGONAL ASSETS}

Workflow optimization has enabled us to achieve, starting from the environmental laser scanner data of a complex space, with strong structural inhomogeneity, a textured polygonal model functional to a passage on Unreal Engine 4 platform for virtual tours with Oculus Rift headset. In the coding, optimization and generation of meshes and textured 3D assets, a series of software and plug-ins were used, through which it was possible to digitally reconfigure the complex of the catacombs of San Vittorino: an architecture, although not excessively extensive, the modelling of which required a particular effort due to a series of problems related to the transfer of the acquired visual photographic data, in order to obtain textures and UVMap projection, together with some critical issues regarding the polygonal correction of some gaps and, in the process of passing on an interactive platform, various assumptions for the arrangement of light sources aimed at a credible management of virtual illuminations. For the occasion, the interactive Ray tracing and the path tracing of Unreal 4.22, based on the use of the new RTX 2080 graphics cards, was also experimented, which allowed an effective real-time rendering, without the use of the canonical techniques of Light Baking. In this regard, it was essential to follow specific measures to maximize the optimization of three-dimensional assets in order to make them light in terms of digital weight, while remaining in a form not simplified.

The operations were carried out taking into account the point cloud most recently acquired by the 2019 survey campaign and processed with the software SCENE_2018.0.0.648 by FARO with a resolution corresponding to a point density of $6.1 \mathrm{~mm}$ at 10 meters from the instrument (resolution $1 / 4$ ), which, containing cameras there is also less detail of the color data imprinted on the point cloud analyzed compared to the color information that would have been obtained from operations of three-dimensional photogrammetric survey; an integrated survey of both techniques would not have been possible in the light of the poor lighting conditions due to the case study under examination. The pug-in Poisson Surface Reconstruction, integrated in the Cloud Compare software, was used for meshing, creating a three-dimensional polygonal model that preserves the correct arrangement of the normal and the color component such as Color Vertex Map, a system that is compatible with most compositing and rendering programs and subsequently fundamental for obtaining the textures (fig. 5). Each vertex of a mesh can store an RGB color value and possibly a monochrome black and white value that the computer interprets as an alpha map of the vertex, which can be used to obtain through some generative algorithms not only the diffuse channel or albedo, or the actual component of material color applied to the model, but also special effects that affect the visual plastic rendering of the $3 d$ asset, such as transparency, environmental occlusion, the Bump or the Normal map. When used for non-chromatic effects, each color channel is generally treated as a separate set of monochromatic values, so, for example, the color of the RGB vertex can control three different per-vertex eff. In our case study, as mentioned above, the acquired color data were not repositories of a detail in HD but thanks to the basic threedimensional information from laser scanners, it was possible to achieve a satisfactory result. The model obtained of the entire complex was then scaled and exported to another software, Pixologic Zbrush, 3d sculpting software very popular among artists and used mainly in the film industry, as a function of some excellent features, such as automatic rhetopology, cloning of HD detail and vertex color components and the creation 
functions of UVmap (fig.7). The first operation was therefore to duplicate each 3D asset in two versions, one subject to polygonal optimization through Z-Remesher, which allowed a quod rhetopology based on morphological recognition of the model through AI functions, so as to obtain a lighter version of 25922 poly, and the other, with
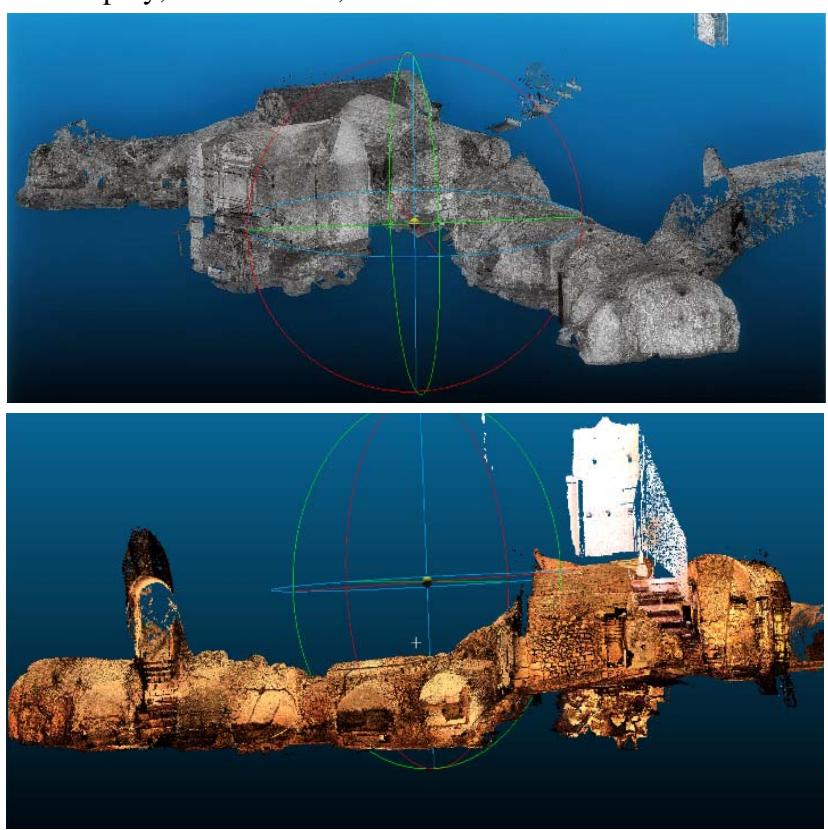

Figure 5. Cloud Compare meshing workflow from Laser scanner cloud points, Poisson Surface Reconstruction.

actual HD detail, of 7894210 poly, custodian of the color component and maximum resolution, unmanageable in any case in migration operations on RTR platforms (Rendering Real Time). Thanks to a third-party Plug-in, ZWrap, it was possible to clone the detail and color vertex of the high-density sample model onto the optimized target model, managing operations through a series of polygonal subdivisions at the same time.(fig.6) This methodology allows to easily exploit the voxel subdivision to make the new asset generated more dense at the polygonal level in accordance with its correct topological morphology.

Once a new mesh quod has been obtained for the 3d models, it is possible to increase the levels of subdivision in a nondestructive way, thus maintaining the lower polygonal levels. The next step allowed to generate the UV Map on the lowdensity model, using two integrated techniques, Group UV Tile projection, which associates a different portion of the textures mapped to each UV Group according to automatic algorithms, without however ensuring the continuity of the maps but compressing well within a single texture portions of color from complex models, and selective wrapping with UV Master, a better method but very time-consuming, which ensures optimal continuity of the maps in view of a possible future $2 \mathrm{~d}$ correction. The vertex color data, called in Zbrush polypaint, are then transformed into RGB color data on Texture, a system that is fundamental for export to Unreal, since the program better supports UVMap and physically correct BPR shaders that use only textures. The textures obtained refer to the Diffuse, Occlusion, Bump/Displacement and Normal Map channels. The creation of complex shaders of this type guarantees an attractive visual result for the virtual tour on Unreal Engine. (Palestini, Basso, 2017). The most popular digital formats that allow better export and import for the management of assets for interactive platforms are the Autodesk .obj and .FBX, capable of containing all the materials and textures previously assigned, the possible positions and movements of the camera and any arrangements of the lights.

Unreal Engine 4.22's real-time graphics rendering technology has reached levels of photorealism closer and closer to those of the most famous pre-calculated rendering engines, based on CPU processors, such as V-Ray and Arnold Render.

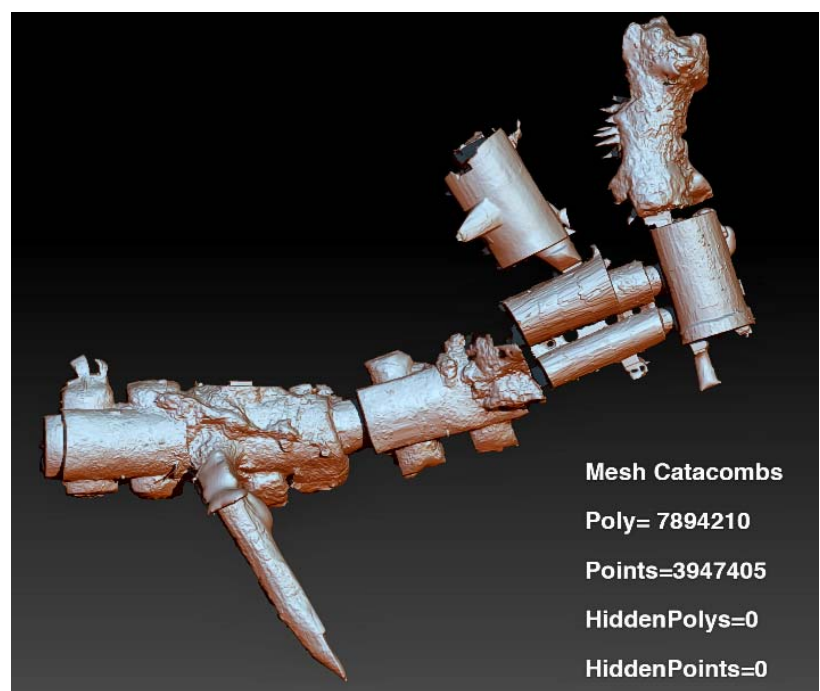

Figure 6. Importing the HD mesh model on Zbrush software, preparing for polygonal optimization.

Platform-managed, physically correct/unbiased BPR shaders not only use Normal and Displacement maps to return the detail of the original high-resolution polygonal model to the optimized model, but also correctly simulate the behavior of real materials, such as translucency, reflection and refraction. Instead of the Texture Baking methodology, where light and shadow effects are directly imprinted on textures, significantly lightening the weight of calculations and defining the lighting once so that it does not have to be recalculated for each frame during interactive exploration, we chose to experiment with Raytracing real time, equipped with an NVIDIA GPUs RTX 2080.

The potential in lighting (lights and shadows) and in the reflections obtained, which significantly reduce the qualitative gap with respect to the previous rendering system, is truly remarkable. Using the hybrid technology of Unreal Engine 4.22, we took advantage of the hardware acceleration of the new NVIDIA GPUs RTX 2080, eliminating the calculation time of the light map and minimally using the "Build" function of Unreal for the texture Baking. The use of this executive workflow for the creation of 3d assets optimized for RTR exploration, has given excellent graphical and visual results, with the only criticality of not being able to exploit textured maps in hd due to the lack of material. Although the technical interface of Unreal is really clear and intuitive, the procedures of Node-System editing and Blueprint, used by the program to manage mapping, texturing and interactions, are still a bit complex, because it requires at least a basic preparation of programming, still not accessible to everyone. We also used a preset, specific for the virtual navigation scenes, which allowed to use some pre-filled features that have streamlined the construction of the final scene. ( fig. 8)

As for the implementation of the Oculus Rift, the system, thanks to sophisticated gyroscopes and motion sensors recognized in real time by the software, responds well to the movements of the head and the positioning of the optical cone despite the limited possibility of movement of the reconfigured scenario. In general, everything works quite well, both in the desktop exploration version and in the immersive version with 
the oculus. The compression and export of the work on the most common external portable platforms, compatible with the systems of windows, macs and game consoles, as well as compatible with simpler virtual reality systems such as cardboard, are a further strength for a possible development of App or serious game to support a larger project on Heritage education or to support a local virtual museum of the catacombs.(fig. 8)

\section{CONCLUSIONS AND FUTURE PERSPECTIVES}

If the cultural heritage is "a group of resources inherited from the past which people identify, independently of ownership, as a reflection and expression of their constantly evolving values, beliefs, knowledge and traditions" (Convenzione di Faro, Consiglio d'Europa, 2005), then we must consider how the digitization of the heritage cannot be interrupted in the documentation phase and the subsequent dissemination of the values of cultural interest.

An additional phase must be considered, because the heritage as well as being documented, preserved and enhancement, to be really handed down to future generations must remain alive, with adequate strategies of re-functionalization, communication or deferred use.

From this point of view we like to think of cultural heritage through an analogy with the genetic heritage: each of us is the result of the genetic heritage handed down by our parents, but in fact it is not "only" that heritage, but something more, something current, something current, so the heritage interests us as a set of evolving values, beliefs, knowledge and traditions handed down, but still made alive thanks to the possibilities of digital technologies, for example. So not the cult of history, but the enhancement of history in our time and for our future.

This approach is in line with one of the UNESCO recommendations "Managing Cultural World Heritage" (2013), for which conservation actions include some trend topics of scientific discussion, such as participation, sharing, sustainability, use of digital technologies.

Participation, Sharing and Sustainability through digital technologies to which, in the development perspectives of this work, is added Education (Luigini, Panciroli, 2018).

In a nutshell, educating about heritage means building the prerequisites for heritage conservation, because a society aware of its heritage is a society that will not allow its impoverishment or oblivion. Educating to heritage also means bringing specialized know-how outside the circuit of experts and scholars interested in heritage, regardless of the conditions of use.

In this sense it is fundamental the possibility provided by the deferred fruition in immersive VR is particularly significant in our case study: the inaccessibility, the geographic location and the need for invasive and not completely reversible interventions for in situ fruition are overcome by the possibility to use the Catacombs of San Vittorino in a convincing manner by means of immersive devices such as the Oculus Rift or similar.

For this reason, in relation to the peculiarities of the case study, we designed a survey that could overcome the difficulties of taking photographs and therefore could only be produced by last generation laser scanning. At that point it could also have been possible to manage the point cloud, optimizing it for immersive navigation, but the need to favor a digital experience as close as possible to a real experience, we chose to follow a workflow capable of optimizing the processing phase of the mesh and textures. The resulting methodology, which can be further developed, is, according to the results obtained, an effective work system in the case in which a navigable model in immersive VR of an environment that requires shooting with the peculiarities of the Catacombs of San Vittorino is desired: difficult accessibility, narrow spaces, very poor lighting, uneven surfaces, preservation of decorative artefacts in a state of deterioration.
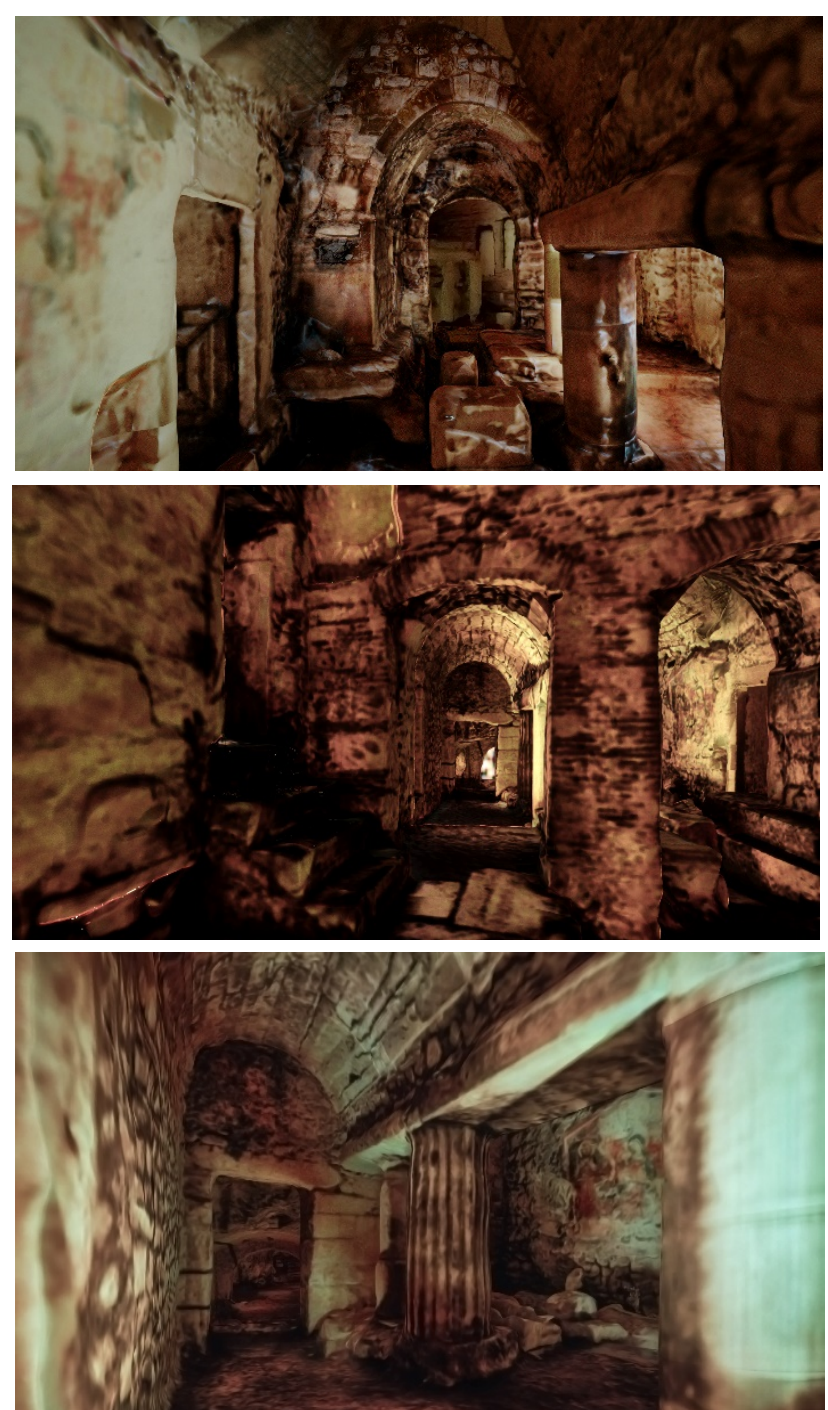

Figure 8. A few frames of the immersive tour inside the digitally reconfigured, textured model of the catacombs, optimized for interactive lighting.

\section{CREDITS}

Although the contribution was conceived jointly by the authors, Ilaria Trizio wrote paragraph 1; Stefano Brusaporci, Alessandra Tata and Pamela Maiezza paragraph 2; Alessandro Basso paragraph 3 and Alessandro Luigini paragraph 4. It is possible to attribute to Alessandro Giannangeli all the phases related to the elaboration of the three-dimensional photogrammetric model of the case study and to Andrea Ruggieri the realization and elaboration of the laser scanning survey. 


\section{ACKNOWLEDGEMENTS}

The research unit of L'Aquila University has received funding from the Italian Government under Cipe resolution n.135 (Dec. 21, 2012), project INnovating City Planning through Information and Communication Technologies (INCIPICT). The research unit of Faculty of Education of Brixen has received funding from CRC Central Research Commission of Free University of Bozen, project Virtual and Augmented Reality for Arts and Heritage in Education and Museum Experience (VAR.HEE).

\section{REFERENCES}

Battini, C., Vecchiattini, R., 2018. Immagini HDR per la documentazione tridimensionale dei manufatti storici. In Salerno, R. (Ed.), Rappresentazione materiale/immateriale Drawing as (in) tangible. Gangemi Editore, Roma, pp. 311-318.

Beraldin, J. A., Picard, M., Valzano, V., Bandiera, A., Negro, F., 2011. Best Practices for the 3D Documentation of the Grotta dei Cervi of Porto Badisco, Italy. Proc. SPIE 7864, ThreeDimensional Imaging, Interaction, and Measurement, 78640J (27 January 2011); https://doi.org/10.1117/12.871211.

Bianchini, C., 2014. Survey, Modeling, Interpretation as multidisciplinary components of a knowledge system. SCIRESIT, 4 (1), 15-24.

Bianchini, C., Ippolito, A., Bartolomei, C., 2015. The Surveying and Representation Process Applied to Architecture: NonContact Methods for the Documentation of Cultural Heritage. In Brusaporci, S. (Ed.), Handbook of Research on Emerging Digital Tools for Architectural Surveying, Modeling, and Representation. IGI Global, Hershey (PA), pp.44-93.

Bonacini, E., D'Agostino, G., Galizia, M., Santagati, C., Sgarlata, M., 2013. Hidden cultural landscapes: survey and digital enhancement of the catacombs of San Giovanni in Syracuse. In: Heritage Architecture Landesign, Focus On Conservation Regeneration Innovation. Le vie dei Mercanti - XI Forum Internazionale di Studi. La scuola di Pitagora, Napoli, pp. 262-271.

Bortolotti, A., Calidoni, M., Mascheroni, S., Mattozzi, I., 2008. Per l'educazione al patrimonio culturale 22 tesi. Franco Angeli, Milano.

Brusaporci, S., Trizio, I., Ruggieri, G., Maiezza, P., Tata, A., Giannangeli, A., 2018. AHBIM per l'analisi stratigrafica dell'architettura storica. Restauro Archeologico, vol. 27, n. 1/2018, 112-131.

Clini, P., Nespeca, R., Angeloni, R., and Mammoli, R., 2019. The Integrated Survey of Narrow Spaces and Underground Architecture: The Case Study of Campana Caves Bas-Reliefs. In: The International Archives of the Photogrammetry, Remote Sensing and Spatial Information Sciences, XLII-2/W9, 277-282, https://doi.org/10.5194/isprs-archives-XLII-2-W9-277-2019.

Gaiani, M., 2012. Per una revisione critica della teoria del rilievo dopo l'avvento dei mezzi digitali. In Carlevaris, L., Filippa, M. (Eds.), Elogio della teoria. Identità delle discipline del disegno e del rilievo. Gangemi Editore, Roma, pp. 375-382.
Luigini, A., Ed., 2019. Proceedings of the 1st International and Interdisciplinary Conference on Digital Environments for Education, Arts and Heritage. Springer, Cham (CH).

Luigini, A., Brusaporci, S., Basso, A., Vattano, S., Maiezza, P., Trizio, I., Tata, A., 2019. Digital experience for the enhancement of cultural heritage. VR and AR models of the Valentin im Viertel farmhouse. In T. Empler, A. Fusinetti (Eds.), Modelli e soluzioni per la digitalizzazione. DEI, Roma, pp. 434-450.

Luigini, A, Panciroli, C., 2018. Ambienti digitali per l'educazione all'arte e al patrimonio. Franco Angeli, Milano.

Moreira, A., Quattrini, R., Maggiolo, G., and Mammoli, R., 2018. HBIM Methodology as a Bridge Between Italy and Argentina. In: The International Archives of the Photogrammetry, Remote Sensing and Spatial Information Sciences, Vol. XLII-2, pp. 715-722.

Pani Ermini, L., 1975. Il santuario del martire Vittorino in Amiternum e la sua catacomba. In: Quaderni storico-artistici dell'Aquilano.

Paris, L., Inglese, C, Wahbeh, W, Maiezza, P., Rossi, M. L., 2016. Art and technique of Roman bridges. The Augustus Bridge in Narni. Landscape \& Archeology. I QUADERNI DI CAREGGI, 141-148. Uniscape, ISSN: 2281-3195.

Nespeca, R., 2018. Towards a 3D digital model for management and fruition of Ducal Palace at Urbino. An integrated survey with mobile mapping. SCIRES-IT, 8 (2), 1-14.

Palestini, C., Basso, A., 2017. Geomatics as a survey tool to document and enhance the cultural and landscaped heritage of the monumental complexes in the mountains of Abruzzo. In: The International Archives of the Photogrammetry, Remote Sensing and Spatial Information Sciences, XLII-5/W1, pp. 373380.

Rodriguez-Navarro, P., Ed., 2017. Archaeological Drawing. Disegnarecon, 10 (19).

Sidor, A.W., 2016. La tomba di S. Vittorino e le sue formulazioni monumentali. Studia Elblaskie, vol. XVII, 93-116.

Somma, M.C., 2012. Il santuario di S. Vittorino ad Amiternum: formazione e trasformazioni di uno spazio cultuale. In: A. Coscarella, A., De Santis, P. (a cura di), Martiri, santi, patroni: per una archeologia della devozione. Atti X congresso nazionale di archeologia cristiana. Arcavacata di Rende (CS), Dipartimento di archeologia e storia delle arti, Università della Calabria.

Trizio, I., Continenza, R., Redi, F., 2017. Heritage Interpretation: a tool for conservation, protection and management of Environmental and Cultural Heritage. SCIRESIT, 7 (1), 39-44. 
The International Archives of the Photogrammetry, Remote Sensing and Spatial Information Sciences, Volume XLII-2/W15, 2019 27th CIPA International Symposium "Documenting the past for a better future", 1-5 September 2019, Ávila, Spain

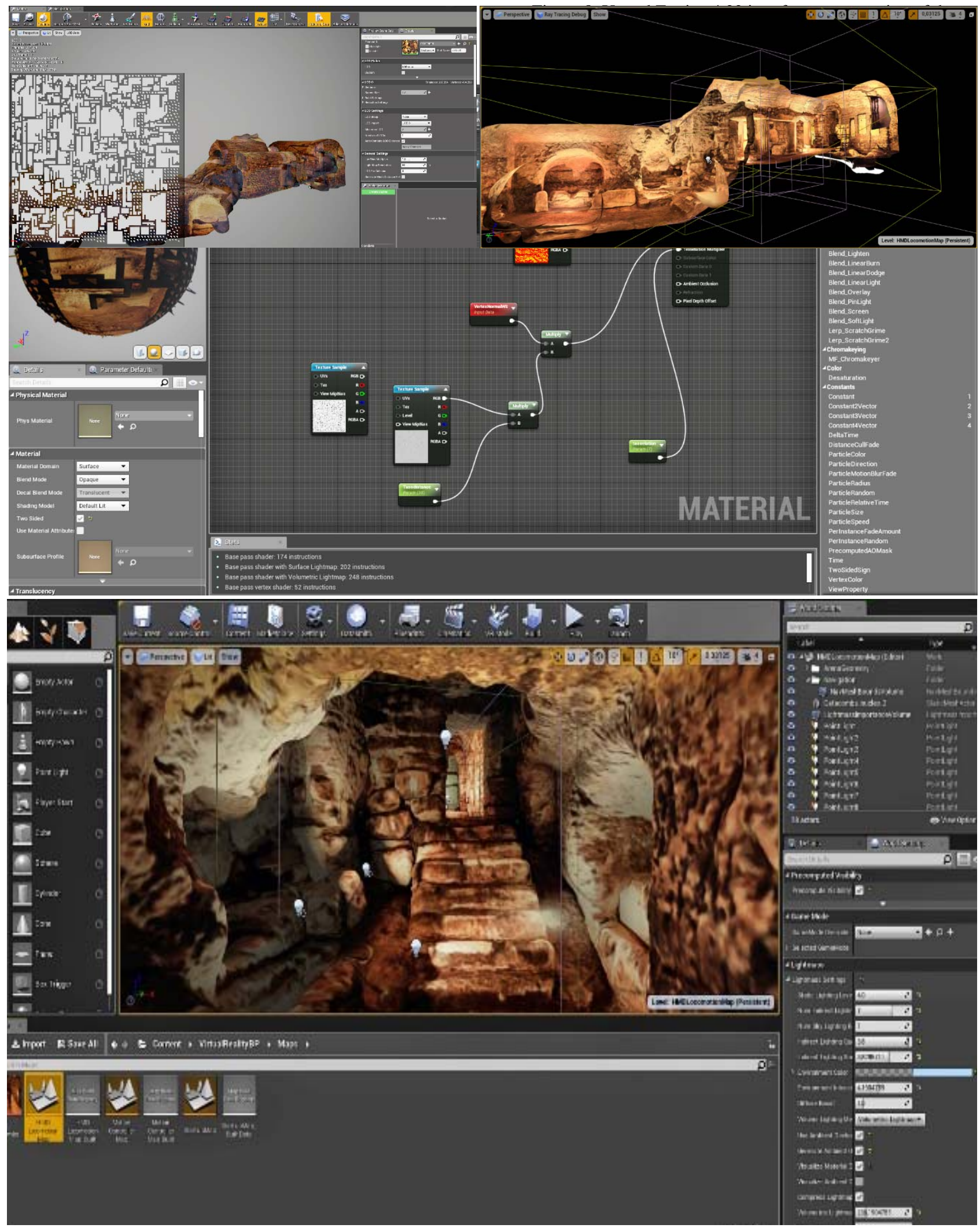

